
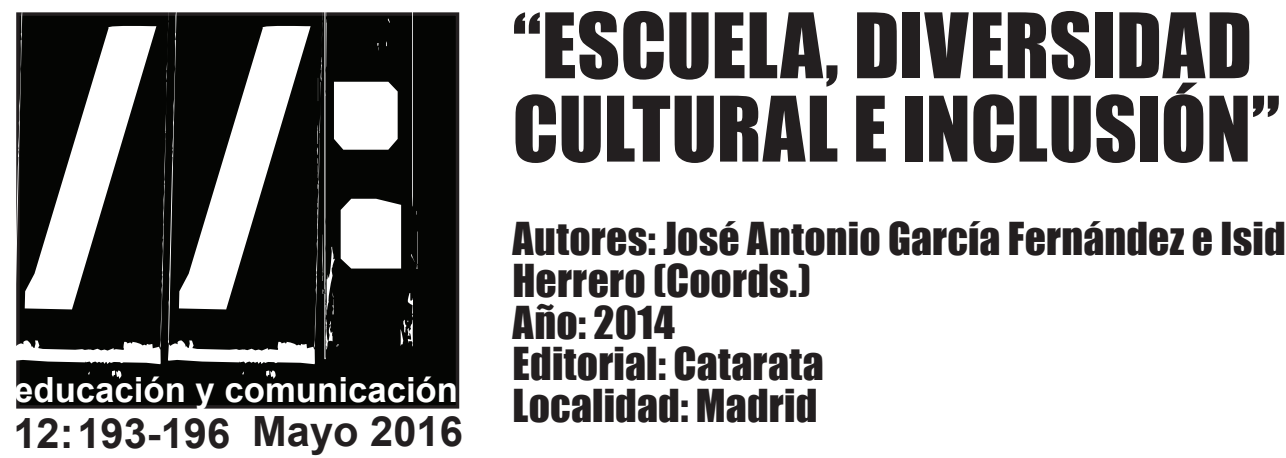

Autores: José Antonio García Fernández e Isidro Moreno Herrero [Coords.]

Año: 2014

Editorial: Catarata

Localidad: Madrid

Víctor Amar

Grupo de Investigación HUM 818

"Educación y Comunicación"

Universidad de Cádiz

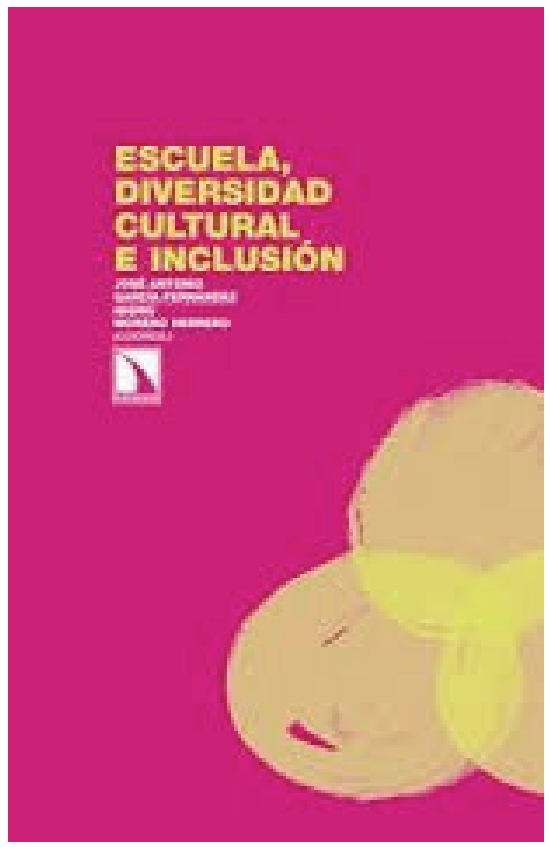


$\mathrm{C}$ onsidero que no es por casualidad que un determinado libro llegue a nuestras manos, para su ulterior lectura. En esta ocasión, fue a través de la coordinadora del presente monográfico, nuestra compañera Cristina Goenechea Permisán, quien lo dejó en mi casillero para la elaboración de la reseña por alguien del grupo de investigación. En este sentido, llevado por la curiosidad y por lo atractivo del título de libro empecé a ojearlo. Y, tal vez, ya no pude dejar de leerlo. He de reconocer lo mucho que me queda por aprender y, sobre todo, en temas de diversidad e inclusión. Sensible, por supuesto, a estas temáticas pero que son realmente amplias y que requieren una profesionalización, comencé su lectura. Sin embargo, llevado por mi afán formativo que nutre mi desarrollo profesional y personal no pude, insisto, dejar de leerlo. Y este libro es un buen ejemplo de ello: de los que te enseñan y te hacen pensar en lo mucho qué nos queda por aprender.

Me preocuparon conceptos que aparecen como es el de la posible homogeneidad de la escuela, a través del sistema educativo. Así mismo, están presentes aspectos relacionados con la discriminación o exclusión, además del de la desigualdad pero siempre abriendo horizontes para la reflexión y el análisis desde dónde están los límites políticos o culturales y en dónde deben saltar las alarmas en la educación (y digo también en la administración educativa). Lógicamente, uno no deja de cuestionar qué es la normalidad (según desde dónde se mire o apunte), o bien a qué llamamos diversidad (si todos lo somos o la sentimos y, a veces, padecemos). Y cuando terminamos de leer el libro, hemos aprendido muchas cuestiones relacionadas con este importante conocer pero, también, qué o para cuándo la llamada inclusión de calidad.
Y, quizás, no sea casualidad que los dos coordinadores del texto, José Antonio García Fernández e Isidro Moreno Herrero, sean profesores de la Universidad Complutense de Madrid, pero, antes de nada dicen ser: "Maestros". Es decir, de la práctica a la teoría, o viceversa. Es un elemento que nutre al libro. Luego se sustenta con aportaciones de otros tantos autores que engrandecen la mirada y llegan a proponer un desafío para ver si somos capaces de completar la cuadratura del círculo entre escuela, diversidad cultura e inclusión; aunque aún nos sigue faltado un lado, para que sean los cuatro de un hipotético cuadrado. Es ahora cuando el lector debe entrar en acción y buscar para proponer qué es lo que falta (o sobra) a partir de los tres anteriores.

Sensibles y sensibilizados a partir de un pensamiento que persigue hasta ahora mi singladura vital que es la misma que comparte con nosotros, José Antonio García Fernández, en el primer párrafo de la introducción, dice: “(...) el análisis y la redefinición urgente de las funciones y prácticas de la institución escolar para formar ciudadanos capaces de vivir en una sociedad plural e igualitaria". Claro, cohabitar y coexistir con los otros; pues seguro que el de más allá... a mí me ve también diferente y, por eso, la diversidad, que se inspira en la complejidad y a la vez en la multiplicidad, en la variedad y, también, en la diferencia e, igualmente, en la desigualdad.

Contribuir, es lo que hace este libro. Contribuir a la mirada de un gran angular. Ya no hay solo vemos lados o posibles ángulos que configuran el hipotético cuadrado con tendencia circular, o viceversa... Sino un cuadrado que se incluye en un círculo y, por eso, comparten un mismo centro y un mismo foco.

Les animo a la lectura del libro. Más de 200 páginas 


\section{I/: Escuela, diversidad cultural e inclusión}

\section{Reseña}

no se leen en un día. Pues precisan de reflexión. Les aconsejo una lectura serena, ya que nos van a invadir las incógnitas y terminamos, al menos yo, después de su lectura con más preguntas que respuestas... Y ahí

radica la generosidad del libro; de este libro sobre una escuela que contempla la diversidad y que incentiva la inclusión pero ¿¿६i...??? 